\title{
APRENDIZAGEM AUTÊNTICA COM O USO DA ROBÓTICA EDUCACIONAL NO ENSINO DE SISTEMAS EMBARCADOS
}

\section{RichARd JUNIOR MANUEL Godinez TeLLO}

Instituto Federal do Espírito Santo

E-mail: richard@ifes.edu.br

\section{MARIZE LYRA SILVA PASSOS}

Instituto Federal do Espírito Santo

E-mail:marize@ifes.edu.br

\section{RESUMO:}

A Robótica Educacional ou Pedagógica é uma metodologia de ensino que objetiva fomentar no aluno a investigação e materialização dos conceitos aprendidos, indo muito além da construção de projetos e programação de robôs. Proporciona uma aprendizagem prática e autêntica que desenvolve no aluno a capacidade de pensar e achar soluções aos desafios propostos. Este trabalho objetiva analisar a percepção dos alunos quanto ao uso da aprendizagem autêntica com o apoio do uso da robótica educacional na aprendizagem de sistemas embarcados. Nesta abordagem, foram utilizadas ferramentas educacionais como a plataforma de prototipagem eletrônica Arduino, os softwares Scratch,Tinkercad e Padlet, para o aprendizado de noções em robótica com o intuito de melhorar o raciocínio lógico dos alunos. Após vinte e uma enquetes realizadas $(n=21)$, utilizando-se a análise ANOVA obtivemos que a média de satisfação com referência à abordagem foi positiva, motivando o interesse dos alunos pela disciplina.

\section{PALAVRAS-CHAVE:}

Aprendizado Autêntica; Robótica Educacional; Automação Industrial; Sistemas Embarcados.

\section{AUTHENTIC LEARNING WITH THE USE OF EDUCATIONAL ROBOTICS IN THE TEACHING OF EMBEDDED SYSTEMS}

\begin{abstract}
:
This work aims to analyze the students' perceptions regarding the use of authentic learning with the support of the use of educational robotics in the learning of embedded systems. Educational or Pedagogical Robotics is a teaching methodology that aims to promote in the student the investigation and materialization of the concepts learned, going much beyond the construction of projects and robot programming. It provides a practical and authentic learning that develops in the student the capacity to think and to find solutions to the proposed challenges. In this approach, educational tools such as the Arduino electronic prototyping platform, the Scratch, Tinkercad and Padlet, software was used to learn robotic notions in order to improve students' logical thinking. After twenty-one surveys $(n=21)$, using the ANOVA analysis, we obtained that the average satisfaction with reference to the approach was positive, motivating students' interest in the subject.
\end{abstract}


KEYWORDS:

Authentic Learning; Educational Robotics; Industrial Automation; Embedded Systems.

\section{INTRODUÇÃO}

O aprendizado autêntico, baseado na aprendizagem e resolução de problemas do mundo real não é novo. E, foi o principal modo de instrução para os aprendizes que mais tarde ocuparam seus lugares dentro de corporações de ofício. Houve uma época em que a aprendizagem em local de trabalho e com base em problemas reais era a forma mais comum de aprendizado. No entanto, à medida que o número de estudantes cresceu no século XIX, a logística e a economia do transporte de um grande número de estudantes para locais de trabalho relevantes tornaram impraticáveis este tipo de aprendizagem em grande escala (HERRINGTON et al., 2003).

Segundo Lombardi (2007) atualmente, neste modelo de aprendizagem muitos estudantes afirmam que se sentem mais motivados quando precisam resolver problemas do mundo real e que aprendem mais, e melhor, quando estão colocando em prática o que aprendem do que quando estão somente escutando o que os professores falam. Mas, por muito tempo trazer problemas reais para a sala de aula foi difícil, principalmente nas áreas de engenharia, pois muitas experiências eram perigosas, difíceis ou caras.

O desenvolvimento de novas ferramentas tecnológicas veio ajudar os professores a trazerem experiências mais reais para seus alunos, promovendo uma aprendizagem mais autêntica. Ou seja, uma aprendizagem que geralmente se concentra em problemas complexos, reais e soluções, usando exercícios e atividades baseadas em problemas, estudos de caso e participação prática em comunidades virtuais. Os ambientes de aprendizagem são inerentemente multidisciplinares. Um ambiente de aprendizagem é semelhante a uma aplicação ou disciplina do "mundo real": gerenciar uma cidade, construir uma casa, fazer voar um avião, estabelecer um orçamento e mais outras aplicações da vida corriqueira (LOMBARDI, 2007). 
A construção de conexões exigirá novas formas de aprendizado autêntico formas que vão além das disciplinas e levam os alunos a um contato significativo com os futuros empregadores, clientes e colegas que terão o maior interesse em seu sucesso. Com isso, iremos quebrar a marca registrada da escola da separação entre teoria e prática e, para isso, sem dúvida, a tecnologia desempenha um papel de apoio importante nesse processo.

Como citado anteriormente nossos alunos precisam ver significado ao que estão aprendendo e com este propósito esta pesquisa teve como objetivo geral analisar a percepção dos alunos quanto ao uso da Aprendizagem Autêntica com o apoio do uso da robótica educacional na aprendizagem da disciplina Sistemas Embarcados do curso Técnico em Automação Industrial Integrado ao Ensino Médio do campus de Serra do Instituto Federal do Espírito Santo.

Para alcançar este objetivo iremos percorrer os seguintes objetivos específicos: propor uma atividade baseada no uso da robótica educacional em espaços de aprendizagem; promover reflexões sobre o uso da aprendizagem autêntica e do uso da robótica educacional; e, por fim, analisar a percepção dos alunos acerca dos recursos da aprendizagem autêntica e do uso da robótica.

O desenvolvimento desta pesquisa tem como fundo um objetivo social de grande importância para o ensino, fazendo uso de problemas reais levados a uma sala de aula, dentro da nova tendência da era da cultura "maker" para a educação e do ensino da robótica educacional nas escolas. Os proponentes dos projetos são engenheiros e professores do Instituto Federal de Ciência e Tecnologia do Espírito Santo com desejo de brindar a melhor qualidade de ensino na instituição. 


\section{REFERENCIAL TEÓRICO}

\subsection{AprendizAgEM AUTÊNTICA}

O aprendizado autêntico é definido como um aprendizado que é perfeitamente integrado ou implantado em situações significativas da "vida real" (JONASSEN; HOWLAND; MARRA; CRISMOND, 2008). Além disso, afirma-se que na aprendizagem autêntica, os alunos são apresentados a problemas reais ou projetos que têm finalidades realistas.

Além disso, o autor, Audrey C. Rule (2006), projetou quatro princípios que definem experiências autênticas de aprendizado. Esses princípios se referem a: 1) foco em problemas práticos e naturais que imitam a vida real permitindo a comunicação de resultados a indivíduos fora da sala de aula; 2) ser baseado em investigação com ênfase em habilidades metacognitivas; 3 ) incentivar os alunos a participarem de conversas ativas em um ambiente de aprendizagem social; e 4) permitir que os alunos façam escolhas e guiem sua própria aprendizagem baseado em um trabalho significativo e orientado para tarefas (RULE, 2006).

Para Lombardi (2007) os estudantes imersos em atividades de aprendizagem autênticas desenvolvem os tipos de "habilidades" que os alunos iniciantes em qualquer disciplina têm mais dificuldade em adquirir por conta própria, entre elas vale enfatizar as seguintes características:

- O julgamento para distinguir informações confiáveis e não confiáveis;

- A paciência de seguir argumentos mais longos;

- A capacidade sintética de reconhecer padrões relevantes em contextos desconhecidos;

- A flexibilidade para trabalhar em fronteiras disciplinares e culturais para gerar soluções inovadoras. 
Pesquisadores como Reeves, Herrington e Oliver (2002) inferem a existência de 10 elementos presentes nesta abordagem que foram sintetizados por Lombard (2007) como:

1. Relevância do mundo real: as atividades autênticas trazem, tanto quanto possível, atividades que correspondam às tarefas do mundo real dos profissionais da área;

2. Problema mal definido: desafios não podem ser resolvidos facilmente pela aplicação de um algoritmo existente; em vez disso, as atividades autênticas são relativamente indefinidas e abertas a múltiplas interpretações, exigindo que os alunos identifiquem por si mesmos as tarefas e subtarefas necessárias para concluir a tarefa principal;

3. Investigação contínua: os problemas não podem ser resolvidos em questão de minutos ou até horas. Em vez disso, as atividades autênticas compreendem tarefas complexas a serem investigadas pelos alunos durante um período prolongado de tempo, exigindo investimento significativo de tempo e recursos intelectuais;

4. Múltiplas fontes e perspectivas: Os alunos não recebem uma lista de recursos. As atividades autênticas oferecem a oportunidade para os alunos examinarem a tarefa a partir de uma variedade de perspectivas teóricas e práticas, usando uma variedade de recursos e exigindo que os alunos distingam informações relevantes e irrelevantes no processo;

5. Colaboração: o sucesso não é alcançável por um aluno individual trabalhando sozinho. Atividades autênticas tornam a colaboração parte integrante da tarefa, tanto no curso quanto no mundo real; 
6. Reflexão (metacognição): as atividades autênticas permitem que os alunos façam escolhas e reflitam sobre seu aprendizado, tanto individualmente quanto em equipe ou comunidade;

7. Perspectiva interdisciplinar: a relevância não se limita a um único domínio ou especialização de assunto. Em vez disso, atividades autênticas têm consequências que se estendem além de uma disciplina específica, incentivando os alunos a adotar diversos papéis e pensar em termos interdisciplinares;

8. Avaliação integrada: a avaliação não é meramente sumativa em atividades autênticas, mas é integrada perfeitamente à tarefa principal de uma maneira que reflete os processos de avaliação do mundo real;

9. Produtos acabados: conclusões não são meramente exercícios ou subetapas na preparação para outra coisa. As atividades autênticas culminam na criação de um produto inteiro, valioso por si só;

10. Múltiplas interpretações e resultados: em vez de produzir uma única resposta correta obtida pela aplicação de regras e procedimentos, atividades autênticas permitem diversas interpretações e soluções concorrentes.

Para podermos construir ambientes capazes de gerarem aprendizagens autênticas precisamos ter como foco algumas diretrizes, como as citadas por Herrington e Oliver (2000) em sua revisão de literatura sobre ambientes de aprendizado baseados em tecnologia. Essas diretrizes são baseadas na filosofia e nas abordagens construtivistas e, especificamente, na teoria da Aprendizagem Situada. Assim, os ambientes de Aprendizagem Situados são mencionados por estes autores da seguinte forma, este ambiente deve:

1. Fornecer contextos autênticos que reflitam a maneira como o conhecimento será usado na vida real; 
2. Fornecer atividades autênticas;

3. Fornecer acesso a performances especializadas e modelagem de processos;

4. Fornecer vários papéis e perspectivas;

5. Apoiar a construção colaborativa de conhecimento;

6. Promova a reflexão para permitir que as abstrações sejam formadas;

7. Promover a articulação para permitir que o conhecimento tácito seja explicitado;

8. Fornecer treinamento e andaimes aos alunos em momentos críticos;

9. Fornecer uma avaliação autêntica da aprendizagem durante a realização das tarefas.

\subsubsection{ATIVIDADES AUTÊNTICAS}

Uma atividade autêntica deve ser projetada para que os alunos possam resolver problemas vindos de situações reais. A atividade não deve ser demasiadamente bem definida e estruturada para poder exigir dos alunos um pensamento sustentado ao longo de várias horas para poder ser concluído e exigir critérios de pesquisas autênticos que gere uma investigação menos típica, mas mais reflexiva, de um professor, que permite aos alunos a oportunidade de comparar as estratégias de avaliação e refletir sobre os pontos fortes e fracos de cada um (HERRINGTON; OLIVER, 2000).

Herrington e Oliver (2000) afirmam ainda que as atividades autênticas devem ser apresentadas ao aluno de forma realista, como em um memorando ou carta, em vez de simplesmente como uma lista de possíveis atividades, e incluíam restrições genuínas, como prazos. As atividades assumem que os alunos trabalharão em pares ou em pequenos grupos e exigirão que eles examinem o recurso de várias perspectivas. 
O contexto para a técnica de Aprendizado Autêntica precisa ser abrangente, fornecer o propósito e a motivação para o aprendizado e fornecer um ambiente de aprendizagem sustentável e complexo que possa ser explorado em profundidade. Não é suficiente simplesmente fornecer exemplos adequados de situações do mundo real para ilustrar o conceito ou problema a ser ensinado. Ele precisa abranger um ambiente físico que reflita o modo como o conhecimento será usado e um grande número de recursos para possibilitar um exame sustentado de diferentes perspectivas (BROWN et al., 1989; HILL; HANNAFIN, 2001; HONEBEIN et al., 1993; REEVES; REEVES, 1997).

Muitos cursos ignoram o rico potencial de um contexto autêntico, desmembrando os materiais do curso da experiência comum (STERNBERG et al., 1993). Princípios teóricos generalizados e habilidades são ensinadas ao invés de os recursos específicos da situação e os livros didáticos geralmente orientam o currículo e o contexto, em vez das práticas genuínas dos profissionais (SMITH, 2004).

\subsubsection{Elementos dA AprendizAgEM AutÊNTICA}

Além de um ambiente propício e professores preparados, a aprendizagem autêntica precisa de elementos de aprendizagem situados em seu planejamento. A Tabela 1 resume uma relação dos principais elementos de aprendizagem situados.

Quadro 1: Principais Elementos da Aprendizagem Situada. Fonte: adaptado de Herrington e Oliver (2000).

\begin{tabular}{|l|l|}
\hline Elemento de aprendizagem & Diretrizes para implementação \\
\hline $\begin{array}{l}\text { Fornecer um contexto real que } \\
\text { reflita o modo como o }\end{array}$ & $\bullet \quad$ ambiente físico que reflita um uso real; \\
conhecimento será usado na & $\bullet \quad$ um projeto não linear; \\
vida-real & $\bullet \quad$ nenhuma tentativa de simplificação. \\
\hline Propor atividades autênticas & $\bullet \quad$ atividades devem ter relevância no mundo real; \\
& $\bullet \quad$ atividades mal definidas; \\
& $\bullet \quad$ uma única tarefa complexa; \\
& $\bullet \quad$ uma oportunidade para os alunos definirem as tarefas; \\
& $\bullet \quad$ a oportunidade de detectar informações relevantes; \\
\hline
\end{tabular}




\begin{tabular}{|c|c|}
\hline & $\begin{array}{l}\text { - oportunidade de colaborar; } \\
\text { - tarefas que possam envolver diversas áreas. }\end{array}$ \\
\hline $\begin{array}{l}\text { Fornecer acesso a performances } \\
\text { especializadas e modelagem de } \\
\text { processos }\end{array}$ & $\begin{array}{l}\text { - } \text { acesso ao pensamento especializado e processos de } \\
\text { - } \text { acesso a alunos em vários níveis de especialização; } \\
\text { - compartilhamento de histórias; } \\
\text { - acesso ao mundo real. }\end{array}$ \\
\hline $\begin{array}{l}\text { Fornecer vários papéis e } \\
\text { perspectivas }\end{array}$ & $\begin{array}{l}\text { - diferentes perspectivas sobre os temas de vários pontos } \\
\text { - de vista; } \\
\text { - a oportunidade de expressar diferentes pontos de vista; } \\
\text { - a oportunidade de cruzar o ambiente de aprendizagem. }\end{array}$ \\
\hline $\begin{array}{l}\text { Apoiar a construção } \\
\text { colaborativa do conhecimento }\end{array}$ & $\begin{array}{l}\text { - } \quad \text { tarefas que são endereçadas ao grupo e não individuais; } \\
\text { - } \text { grganização da sala de aula em pares ou pequenos } \\
\text { - estrutura de incentivos apropriada para o } \\
\text { desenvolvimento de todo o grupo. }\end{array}$ \\
\hline Promover reflexão & $\begin{array}{l}\text { - } \quad \text { navexte e tarefa autênticos; } \\
\text { - } \text { oportunidade de contato dos alunos com especialistas; } \\
\text { - oportunidade de contato dos alunos com outros alunos; } \\
\text { - trabalhos colaborativos de estudantes. }\end{array}$ \\
\hline Promover a articulação & $\begin{array}{l}\text { - uma tarefa complexa que incorpora oportunidades } \\
\text { inerentes de articulação; } \\
\text { - grupos para permitir a articulação; } \\
\text { - apresentar publicamente argumento para permitir a } \\
\text { defesa da aprendizagem. }\end{array}$ \\
\hline $\begin{array}{l}\text { Fornecer orientação e } \\
\text { crescimento gradativo }\end{array}$ & $\begin{array}{l}\text { - um ambiente de aprendizagem complexo e aberto; } \\
\text { - } \quad \text { projeto multimídia não linear; } \\
\text { - diretrizes para o uso do programa em vários contextos } \\
\text { - aprendizado colaborativo; } \\
\text { - recomendações que o professor esteja disponível para } \\
\text { orientação. }\end{array}$ \\
\hline $\begin{array}{l}\text { As tarefas devem permitir a } \\
\text { avaliação da aprendizagem } \\
\text { autêntica }\end{array}$ & $\begin{array}{l}\text { - fidelidade do contexto; } \\
\text { - } \text { a oportunidade para os alunos criarem peças, } \\
\text { - } \text { temporformances ou produtos acabados; } \\
\text { - desafios complexos, mal estruturados; } \\
\text { - avaliação seja perfeitamente integrada com a atividade } \\
\text { - múltiplos indicadores de aprendizagem; } \\
\text { - validade e confiabilidade com critérios apropriados para } \\
\text { classificar produtos variados. }\end{array}$ \\
\hline
\end{tabular}




\subsection{ENSINO da LógICA de Programação e IMPLEMENTAÇÃo de CIRCUITOS}

Sendo o raciocínio a forma mais complexa do pensamento, a lógica estuda a "correção do raciocínio", colocando ordem no pensamento (FERBELLONE; EBERSPACHER, 2005). Assim, nota-se a importância da lógica na vida, não só como teoria, mas como prática, uma vez que, quando um ser humano quer pensar, falar, escrever ou agir corretamente, necessita colocar "ordem no pensamento", fazendo uso da lógica. A capacidade de abstração é algo fundamental para o sucesso na aprendizagem de programação, principalmente para compreender problemas e propor soluções (ZANETTI; OLIVEIRA, 2015). Desta forma, é necessário fomentar a capacidade de abstração e raciocínio lógico dos discentes para ter resultados proveitosos no processo de ensino-aprendizagem em programação e implementação de circuitos. Para isso, uma forma de desenvolver tal capacidade dá-se pela utilização de jogos ou ferramentas digitais que estimulam o aluno se ater ao objetivo do jogo brincando.

Nas seguintes subseções serão descritas as ferramentas utilizadas para a metodologia proposta:

\subsubsection{A Plataforma Microcontrolada Arduino}

Uma destas formas de ferramentas que motivam o aprendizado brincando, é a ferramenta Arduino. É importante destacar que a plataforma microcontrolada Arduino é um dos principais projetos de hardware open-source amplamente difundido no mundo (MONK, 2013). Muitos projetos ganham vida graças a esta ferramentaplataforma, especialmente o desenvolvimento de produtos de Internet das Coisas (Internet of Things - IoT). Desenvolvedores, engenheiros, estudantes, empresas e makers em geral estão utilizando Arduino para inovar em seus projetos dos mais variados tipos. O Movimento Maker ou "Cultura Criadora" é uma extensão da cultura Faça-Você-Mesmo ou, em inglês, Do-It-Yourself (ou simplesmente DIY). Esta cultura 
tem em sua filosofia a ideia de que pessoas comuns podem construir, consertar, modificar e fabricar os mais diversos tipos de objetos e projetos com suas próprias mãos (ALIMISIS et al., 2017).

O Arduino é uma plataforma de hardware e software livre e está disponível para seu uso e melhorias. Um diferencial desta ferramenta é o fato de ser mantido por uma comunidade com filosofia de open-source, desenvolvendo e divulgando gratuitamente seus projetos. A plataforma Arduino surgiu na Itália, elaborado por Massimo Banzi e David Cuartielles em 2005, com o objetivo de criar um dispositivo que possa ser utilizado em projetos de baixo custo. O sistema é baseado em uma placa microcontrolada, com acessos de Entrada/Saída (I/O), sobre a qual foram desenvolvidas bibliotecas com funções que simplificam a sua programação através de uma Interface chamada Arduino IDE. A programação é baseada numa sintaxe similar à das linguagens C e C++. As plataformas Arduino são baseadas em microcontroladores da empresa Atmega. Um microcontrolador (também denominado MCU) é um computador dentro de um chip, que contém um microprocessador, memória e periféricos de entrada/saída.

A comunidade desenvolvedora de projetos baseados no Arduino é bastante colaborativa ao redor do mundo e os colaboradores ajudam a espalhar o uso da ferramenta através de tutoriais, projetos, fóruns e conteúdos. É importante ressaltar também que o Arduino foi um grande propulsor do movimento maker no mundo todo e sua facilidade de uso permitiu que projetos eletrônicos utilizando os microcontroladores fossem desenvolvidos.

\subsubsection{USO DA FERRAMENTA SCRATCH}

Scratch é um entorno de programação visual e multimídia baseado em Squeak destinada à realização e difusão de sequências animadas com o sem som e como ferramenta de ensino-aprendizagem em programação (MALONEY et al., 2004). 
A ferramenta foi desenvolvida pela Media Laboratórios do Instituto de Tecnologia de Massachusetts (Massachusetts Institute of Technology - MIT) e pelo grupo KIDS da Universidade de Califórnia, Los Angeles. Trabalhando na ferramenta Scratch é possível entender de forma lúdica, os seguintes conceitos matemáticos e informáticos: Processos interativos (bucles ou loops); critérios condicionais (se, então, se-não); coordenadas de um plano; variáveis, etc.

Cada bloco da linguagem contém um comando em separado, que podem ser agrupados livremente caso se encaixem. E os comandos podem ser modificados através de menus barra. A programação é feita a partir de fragmentos de código, embutidos nos blocos de comandos de diferentes cores e formatos, que podem ser arrastados para uma janela onde o programa é construído (ver Figura 2).

Figura 2: Exemplo de programação em Scratch.

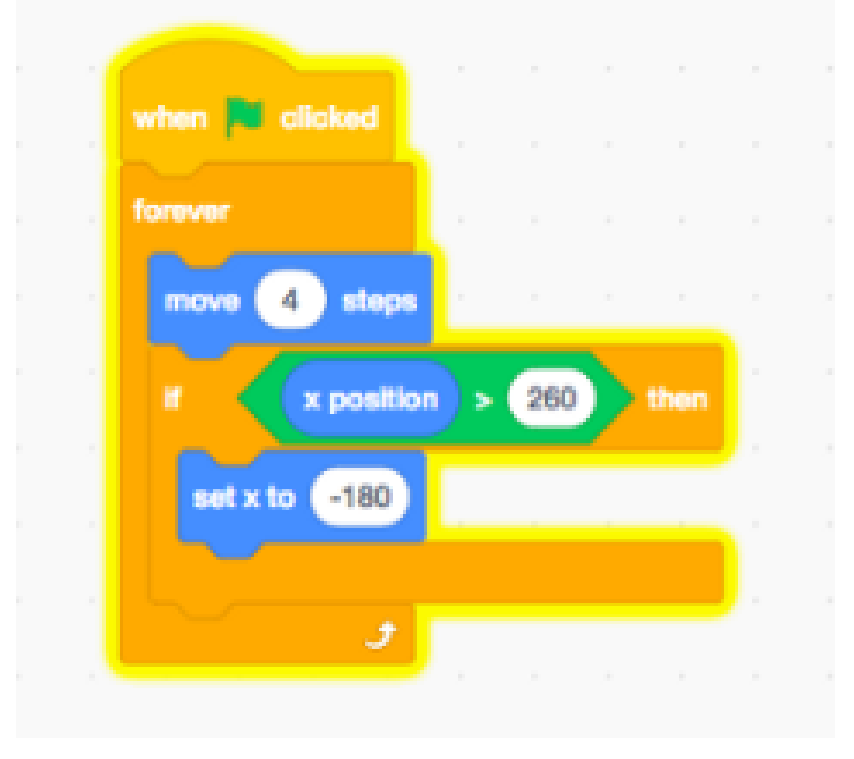

Desta forma, o aluno não precisa de conhecimentos avançados em linguagem de programação, apenas a lógica que existe na escrita de programas. 


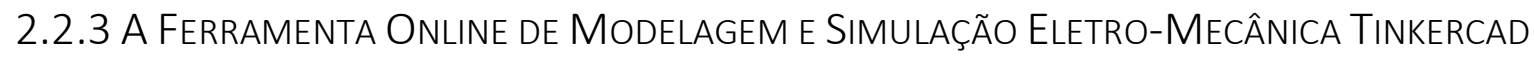

O Tinkercad é uma ferramenta online de design de modelos 3D em CAD e também de simulação de circuitos elétricos analógicos e digitais, desenvolvida pela Autodesk. Por ser gratuito, intuitivo e de fácil entendimento, podemos encontrar nele, uma nova forma de aprendizado usando um laboratório online que contém os componentes eletro-eletrônicos necessários para começar a desenvolver projetos. Uma das principais barreiras que os alunos encontram é a dificuldade de conseguir os componentes para iniciar um teste prévio, razão pela qual a ferramenta é de grande utilidade. Atualmente, a ferramenta permite a simulação de dispositivos mecânicos, elétricos, eletrônicos e visualizar sinais usando ferramentas de medição. A ferramenta indica também se houve alguma sobre tensão ou sobre corrente na hora de realizar alguma conexão, ajudando assim a realizar as correções devidas.

Uma das grandes vantagens do Tinkercad da Autodesk é a dupla modalidade de programação: código C e Scratch. A programação em C para o módulo Arduino é uma das formas tradicionais de programação do sistema microcontrolado, porém o Tinkercad ainda disponibiliza a opção de programar via caixas de fluxo, similar ao Scratch.

Figura 3: Interface de Programação usando Tinkercad.

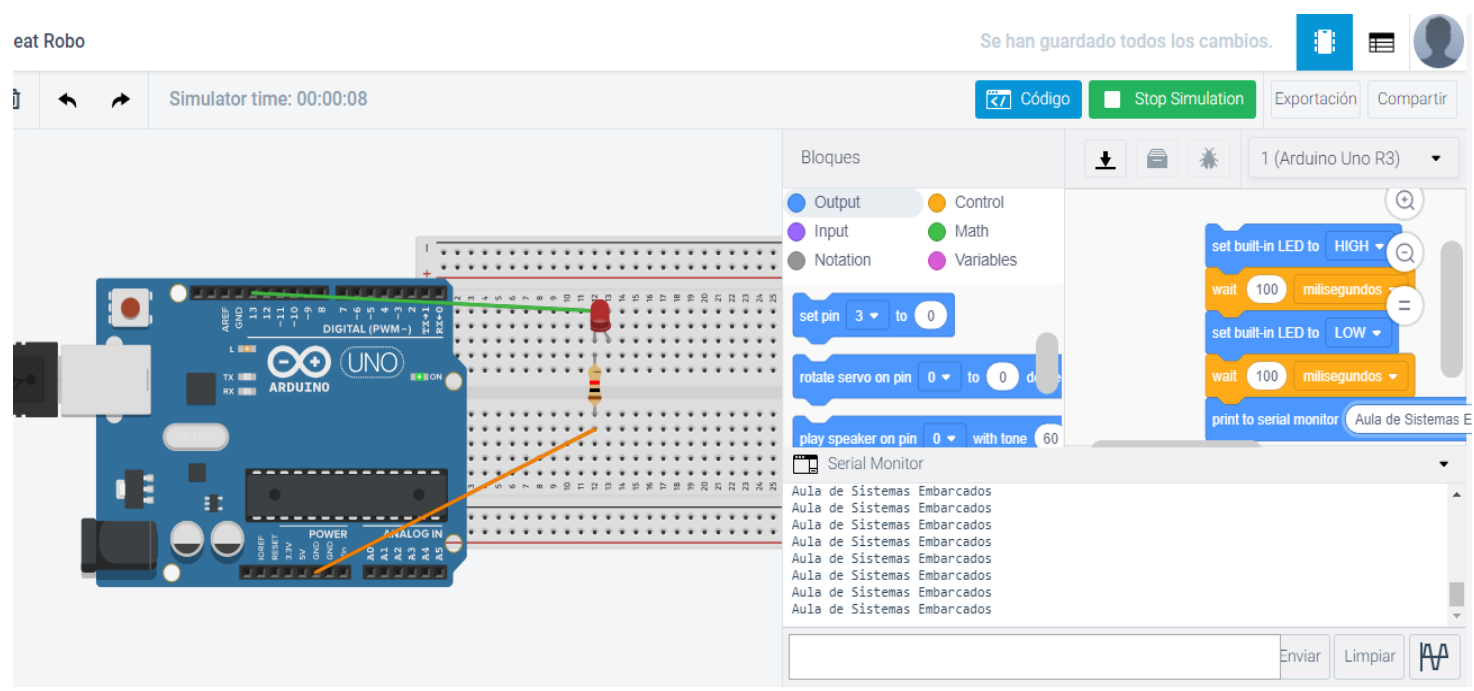


Outra das grandes vantagens do uso da ferramenta Tinkercad, é a possibilidade de simular dispositivos mecânicos, um exemplo destes é mostrado na figura 4, com ela podemos executar a programação de servomotores. Servomotores são essenciais para o controle de robôs móveis e diversos projetos robotizados (como por exemplo, braços robóticos, elevadores, etc.), devido ao controle preciso do giro.

Figura 4: Programação de servomotores usando Tinkercad.

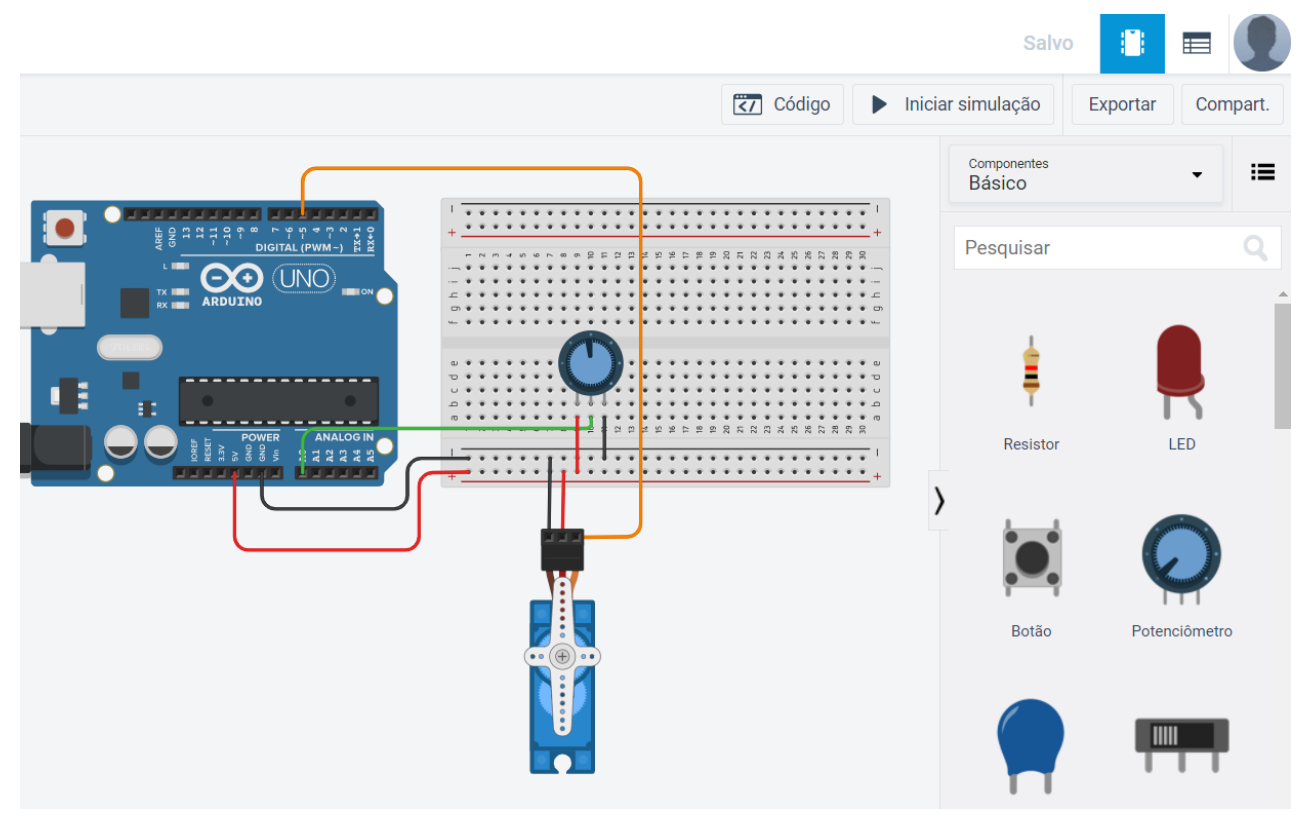

2.2.4 A Ferramenta Online de Compartilhamento de Ideias e Trabalho Colaborativo Padlet

Padlet é uma ferramenta on-line que pode ser usada por participantes convidados para colaborar na coleta de ideias (brainstorming) e compartilhamento de informações. Os participantes podem postar comentários, imagens, vídeos e links sobre qualquer assunto em tempo real e personalizar os espaços de acordo à preferência do grupo e de acordo ao tema (PADLET, 2018). Uma das características principais do Padlet é uso de murais. Assim, o mural do Padlet pode ser visualizado por um grupo privado ou compartilhado de forma pública. Um exemplo de mural virtual pode ser observado na Figura 5. 
Figura 5: Um exemplo dos murais construídos no Padlet apresentados pelos alunos.

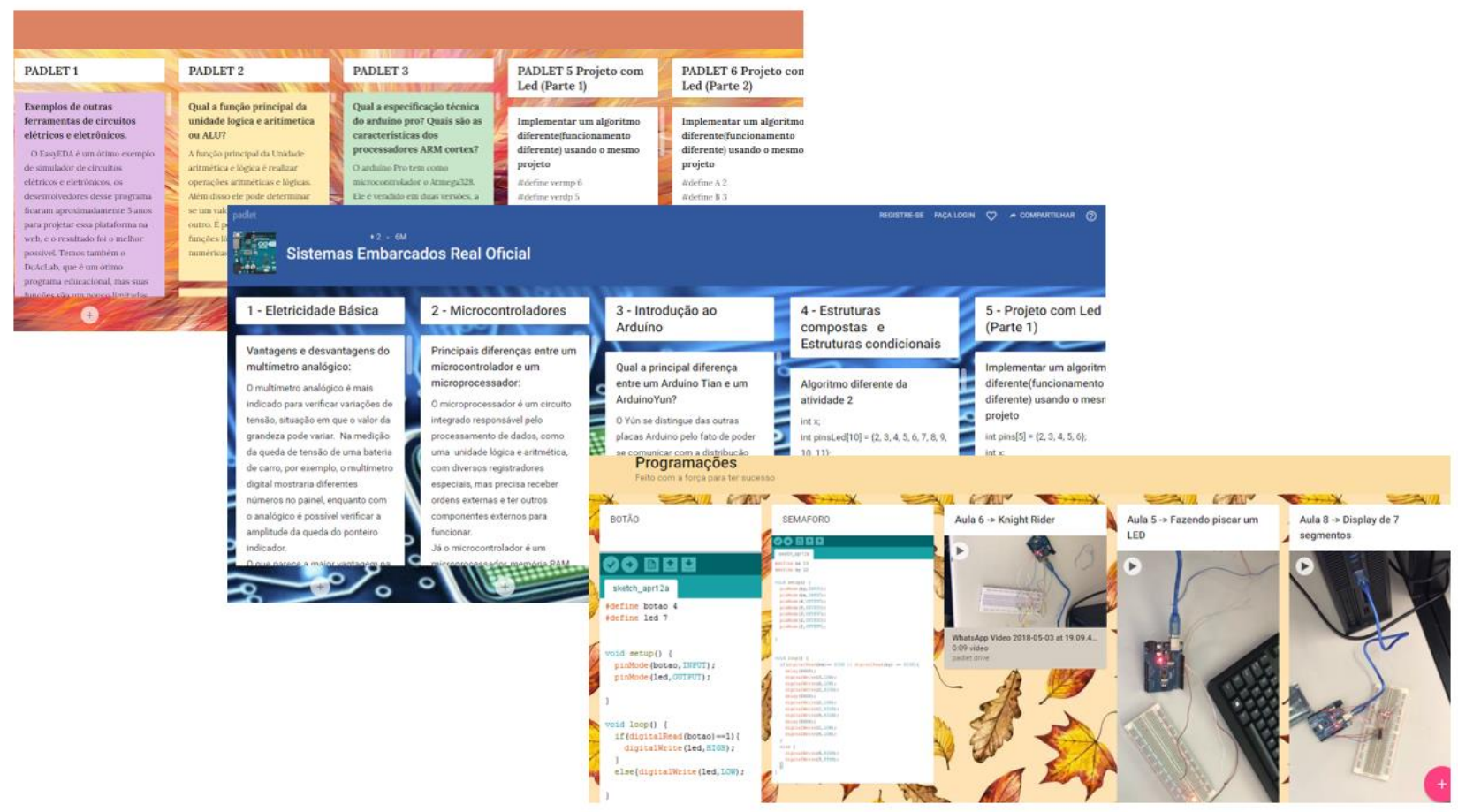

Padlet é um aplicativo gratuito que funciona em qualquer dispositivo inteligente (celulares, tablets e computadores). Recursos adicionais estão disponíveis com os planos premium pagos do Padlet. As várias configurações de privacidade permitem o acesso controlado ao mural e aos direitos dos colaboradores, incluindo a opção de aprovar as contribuições antes de serem exibidas. Uma função útil do Padlet é que as contribuições podem ser feitas anonimamente. O Padlet é uma ferramenta educacional simples, funcional e de grande utilidade para disseminação de ideias (Padlet, 2018).

\section{Percurso Metodológico}

As pesquisas científicas, de forma geral, e na educação, de forma específica, podem ser classificadas quanto à sua natureza; quanto à sua abordagem; quanto aos seus objetivos; e quanto aos procedimentos técnicos escolhidos. 
No caso desta pesquisa específica podemos classificá-la quanto à sua natureza, como Pesquisa Aplicada, pois o seu resultado irá ajudar a outros professores a trabalharem com o conceito de aprendizagem autêntica. Gerhardt e Silveira (2009, p. 35) dizem que a pesquisa aplicada "[...] objetiva gerar conhecimentos para aplicação prática, dirigidos à solução de problemas específicos. Envolve verdades e interesses locais".

A abordagem utilizada nesta pesquisa foi o método misto, ou uma pesquisa quali-quantitativa, como cita Günther (2006, p. 207), “[...] o pesquisador não deveria escolher entre um método ou outro, mas utilizar as várias abordagens, qualitativas e quantitativas, que se adequam à sua questão de pesquisa". Sampieri, Collado e Lucio (1991) afirmam que um método não neutraliza o outro na tentativa de responder às diferentes questões no campo da investigação de um problema determinado, pois coleta, avalia e vincula dados qualitativos e quantitativos numa mesma pesquisa.

No caso desta pesquisa específica podemos classificá-la quanto ao seu objetivo como pesquisa exploratória que "[...] alguns autores a vem como um estudo inicial para a realização de outro tipo de pesquisa" (RODRIGUES, 2006, p. 90).

Esta pesquisa configura-se como um estudo de caso que segundo Lüdke e André (2014), envolve a obtenção de dados descritivos, obtidos no contato direto do pesquisador com a situação estudada, enfatiza mais o processo do que o produto e se preocupa em retratar a perspectiva dos participantes. Um caso pode ser similar a outros, mas ao mesmo tempo é distinto, pois tem um interesse próprio e singular (LÜDKE; ANDRÉ, 2014). O estudo de caso é caracterizado pelo estudo profundo e exaustivo de um ou de poucos objetos, de maneira a permitir o seu conhecimento amplo e detalhado (GIL, 2009).

A pesquisa foi realizada, com a anuência do Diretor Geral do campus de Serra do Instituto Federal do Espírito Santo, a disciplina de Sistemas Embarcados do curso 
Técnico em Automação Industrial Integrado ao Ensino Médio é uma disciplina anual dividida em 2 semestres.

\subsection{Procedimentos E Coleta de DADOS}

A fim de promover de forma lúdica o ensino da robótica para os alunos do curso Técnico em Automação Industrial Integrado ao Ensino Médio, do campus de Serra, foram realizadas aulas teóricas e práticas por meio de pequenos projetos em laboratório. Para isso, foram utilizadas as seguintes ferramentas para apresentar noções básicas de raciocínio lógico, conceitos, noções de programação e implementação de circuitos, conforme o diagrama de blocos seguinte:

Figura 6: Diagrama de blocos da metodologia proposta.

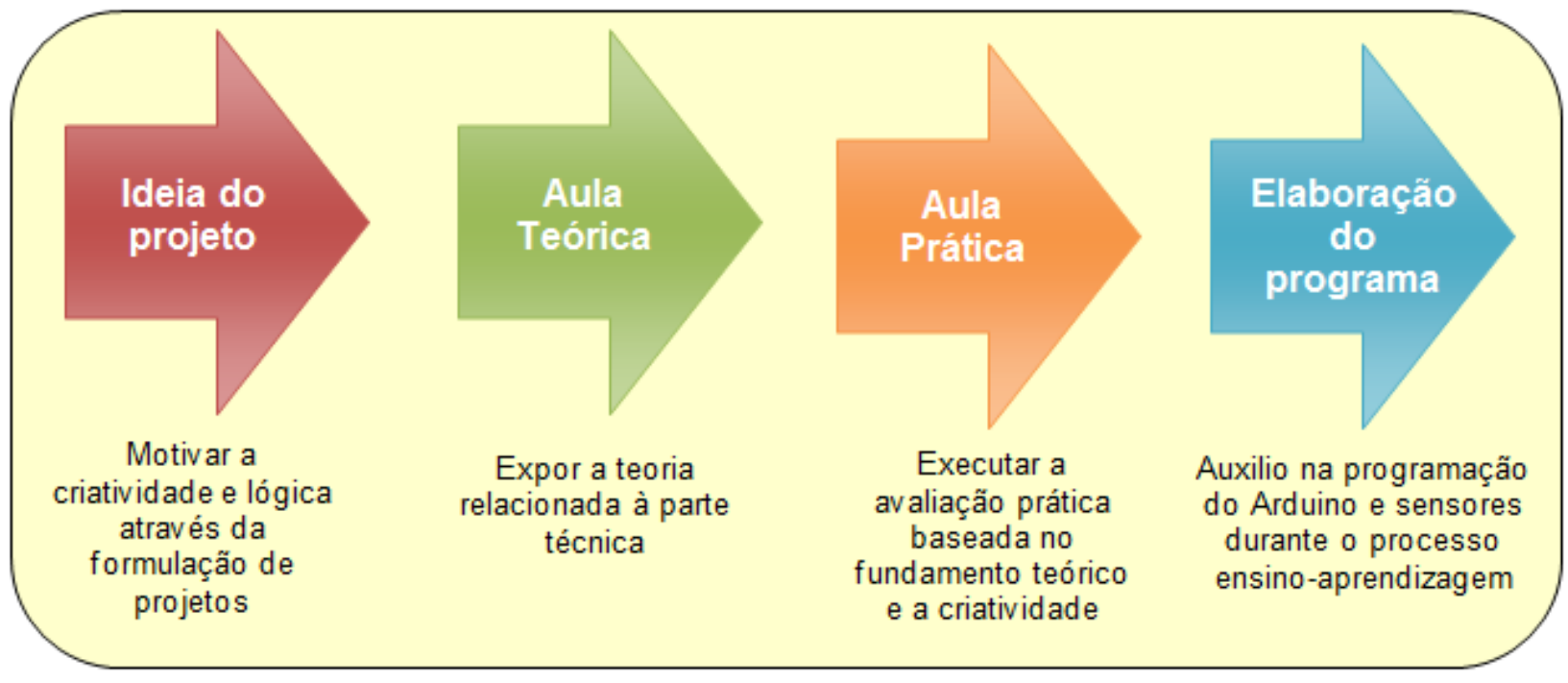

Uma forma de avaliação dos resultados e acompanhamento do aprendizado foi baseada no uso da ferramenta Padlet para visualizar o trabalho colaborativo dos alunos.

A coleta de dados neste trabalho foi realizada utilizando-se dos seguintes instrumentos: uso de aplicativo móvel para realização dos trabalhos de forma 
colaborativa (uso do software Padlet); questionário sobre a percepção dos alunos referente as aulas e registro por meio de fotos.

O questionário utilizado possuía seis questões fechadas e uma aberta. As cinco primeiras questões utilizaram uma escala Likert de 5 pontos que variam de Pouco a Bastante, já a sexta questão foi uma questão com resultado binário (sim/não). E por último foi feita uma questão aberta para que os alunos pudessem colocar sugestões para melhorar a abordagem utilizada. O coeficiente alfa de Cronbach foi apresentado por Lee J. Cronbach, em 1951, como uma forma de estimar a confiabilidade de um questionário aplicado em uma pesquisa. Ele mede a correlação entre respostas em um questionário através da análise das respostas dadas pelos respondentes, apresentando uma correlação média entre as perguntas. O coeficiente $\alpha$ é calculado a partir da variância dos itens individuais e da variância da soma dos itens de cada avaliador de todos os itens de um questionário que utilizem a mesma escala de medição. O valor do alfa de Cronbach calculado para este questionário foi de 0,6 o que significa que o questionário possui uma consistência interna aceitável.

Este questionário foi apresentado de forma impressa e obteve 21 respostas de forma livre, espontânea e voluntária.

\section{ANÁLISE dOS RESULTADOS}

\subsection{Plano De Aula}

Ao se desenvolver projetos baseados em aprendizagem autêntica deve-se priorizar um bom planejamento e capacidade de antecipação de problemas, mapeamento dos recursos disponíveis entre os aprendizes e capacidade de improvisação. Sendo assim foi planejado uma série de atividades a serem realizadas que tinham o objetivo de atender os principais elementos da aprendizagem planejados para serem utilizados durante as aulas de sistemas embarcados e robótica, Quadro 2. 
Quadro 2: Principais Elementos da Aprendizagem Situada. Fonte: adaptado de Herrington e Oliver (2000).

\begin{tabular}{|c|c|}
\hline Elemento de aprendizagem & Atividade Planejada \\
\hline $\begin{array}{l}\text { Fornecer um contexto real que } \\
\text { reflita o modo como o } \\
\text { conhecimento será usado na } \\
\text { vida-real }\end{array}$ & $\begin{array}{l}\text { - Programação de um semáforo, lembrando que esta } \\
\text { programação deve garantir a segurança da passagem de } \\
\text { pedestres na via. Então, deve programar um semáforo para } \\
\text { os carros e o semáforo de pedestres. } \\
\text { - Ativação de dispositivos eletrônicos através de uma } \\
\text { botoeira de pressão. Assim que uma pessoa apertar a } \\
\text { botoeira, um díodoluminoso (LED) deve ser ativo enquanto } \\
\text { o sujeito estiver apertando o botão. } \\
\text { - Programação de um poste de luz inteligente. Usando um } \\
\text { sensor de luz (fotoresistor), o aluno deve programar o } \\
\text { Arduino para que, assim que chegar a escuridão da noite, } \\
\text { uma luz LED deve ser acionada. } \\
\text { Emissão de melodia, uma das formas de identificar a } \\
\text { ligação telefónica de um contato salvo no celular é através } \\
\text { das diferentes melodias que podem ser configuradas, desta } \\
\text { forma, o aluno irá programar um Arduino para que um alto } \\
\text { falante conectado a este possa emitir uma melodia. } \\
\text { - Montagem de circuito eletrônico com displays, } \\
\text { atualmente, vivemos em uma era digital, mas como } \\
\text { faríamos a montagem de um relógio digital com circuitos } \\
\text { integrados? O aluno deverá montar um circuito eletrônico } \\
\text { com displays onde serão mostrados segundos, minutos e } \\
\text { horas. } \\
\text { Controle da velocidade de um motor de corrente contínua } \\
\text { usando modulação por largura de pulsos. Esta modulação } \\
\text { será programada usando o Arduino. A partir da } \\
\text { programação destes motores poderemos criar plataformas } \\
\text { robóticas mais avançadas. }\end{array}$ \\
\hline Propor atividades autênticas & $\begin{array}{l}\text { - No projeto do semáforo, o aluno deve medir o tempo de } \\
\text { mudança das cores com relação à velocidade do caminhar } \\
\text { de uma pessoa relacionado com a distância da passarela. } \\
\text { - No projeto do poste de iluminação pública inteligente, o } \\
\text { aluno deve realizar vários testes para ajustar a sensibilidade } \\
\text { do sensor a um evento real como é a mudança do claro à } \\
\text { escuridão. } \\
\text { - No projeto do relógio digital, o aluno precisará realizar } \\
\text { vários testes para ajustar a unidade temporal de } 1 \text { segundo } \\
\text { para que as mudanças a minutos e horas possam ser as } \\
\text { mais próximas da realidade. }\end{array}$ \\
\hline
\end{tabular}




\begin{tabular}{|c|c|}
\hline 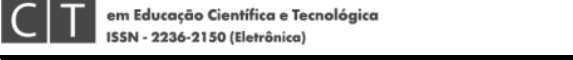 & Revista Eletrônica DECT, Vitória (ES), v. 9, n. 01, p. 248-274, 2019 \\
\hline $\begin{array}{l}\text { Fornecer acesso a performances } \\
\text { especializadas e modelagem de } \\
\text { processos }\end{array}$ & $\begin{array}{l}\text { - Para conseguir esta fase serão necessárias simulações } \\
\text { usando ferramentas computacionais que possam nos } \\
\text { aproximar com eventos similares a um ambiente real. }\end{array}$ \\
\hline $\begin{array}{l}\text { Fornecer vários papéis e } \\
\text { perspectivas }\end{array}$ & $\begin{array}{l}\text { - O aluno terá a possibilidade de ter os pontos de vista de } \\
\text { desenvolvedor, analisando a performance da } \\
\text { programação. Por outro lado, o aluno tem a perspectiva da } \\
\text { avaliação como usuário e possa obter uma perspectiva } \\
\text { crítica do trabalho apresentado. }\end{array}$ \\
\hline $\begin{array}{l}\text { Apoiar a construção colaborativa } \\
\text { do conhecimento }\end{array}$ & $\begin{array}{l}\text { - Os projetos são desenvolvidos em grupo, onde cada aluno } \\
\text { tem uma função específica. Desta forma, existe uma } \\
\text { distribuição do trabalho realizado. Para o professor, uma } \\
\text { forma de avaliação do trabalho colaborativo é a revisão dos } \\
\text { murais (desenvolvido no Padlet) elaborados pelos alunos. }\end{array}$ \\
\hline Promover reflexão & $\begin{array}{l}\text { - Durante a apresentação dos projetos, os alunos de outros } \\
\text { grupos são participantes e críticos dos trabalhos dos outros } \\
\text { grupos. Desta forma, geramos perspectivas diferentes da } \\
\text { abordagem do problema. }\end{array}$ \\
\hline Promover a articulação & $\begin{array}{l}\text { - Cada integrante do grupo explica de forma oral o projeto } \\
\text { desenvolvido diante dos outros colegas dos outros grupos. }\end{array}$ \\
\hline $\begin{array}{l}\text { Fornecer orientação } \\
\text { crescimento gradativo }\end{array}$ & $\begin{array}{l}\text { - O ambiente do desenvolvimento dos projetos é propício } \\
\text { para o aprendizado, devido à infraestrutura do laboratório. } \\
\text { Existem bancadas amplas, ambiente climatizado, bem } \\
\text { iluminado e computadores de última geração. } \\
\text { - Por outro lado, o professor disponibiliza horários de } \\
\text { orientação para absolver dúvidas dos alunos. } \\
\text { - As atividades propostas terão um aumento gradativo de } \\
\text { complexidade. }\end{array}$ \\
\hline $\begin{array}{l}\text { As tarefas devem permitir a } \\
\text { avaliação da aprendizagem } \\
\text { autêntica }\end{array}$ & $\begin{array}{l}\text { - Na elaboração dos projetos, a criatividade é outro ponto a } \\
\text { tomar em conta. Criatividade tanto na forma da } \\
\text { programação e na forma da apresentação dos resultados } \\
\text { são tomados em conta. } \\
\text { - Os alunos serão avaliados durante todo o processo. }\end{array}$ \\
\hline
\end{tabular}

\subsection{ObSERVAÇõEs Sobre A AuLA}

A turma corresponde ao segundo ano do Curso Técnico Integrado em Automação Industrial. Essa turma até o início da disciplina não tinha recebido aulas relacionadas a matérias técnicas específicas, como é o caso da disciplina de Sistemas 
Embarcados. Durante a apresentação da disciplina, no primeiro dia de aula, os alunos se mostraram muito interessados nos temas a serem abordados, a partir da realização de uma contextualização prévia do uso dos sistemas embarcados e da robótica em nossos dias. Isso teve o objetivo de fornecer aos alunos um contexto real para que eles pudessem refletir sobre o modo como o conhecimento adquirido pode ser usado na vida-real.

Foi constatado que não é necessário conhecimentos avançados em eletrônica para o desenvolvimento de projetos relacionados à robótica e sistemas embarcados. A maioria dos projetos requer raciocínio lógico e fundamentos em programação. Ao longo da disciplina, os alunos conseguiram entender o funcionamento de circuitos digitais por meio de problemas vindos da vindo da real fazendo uso das diferentes ferramentas pedagógicas anteriormente citadas e buscando sempre atender aos principais elementos da aprendizagem situada promovendo assim uma aprendizagem autêntica.

Algumas imagens dos alunos montado os circuitos são mostradas a seguir na Figura 7:

Figura 7: Alunos apresentando os projetos desenvolvidos.
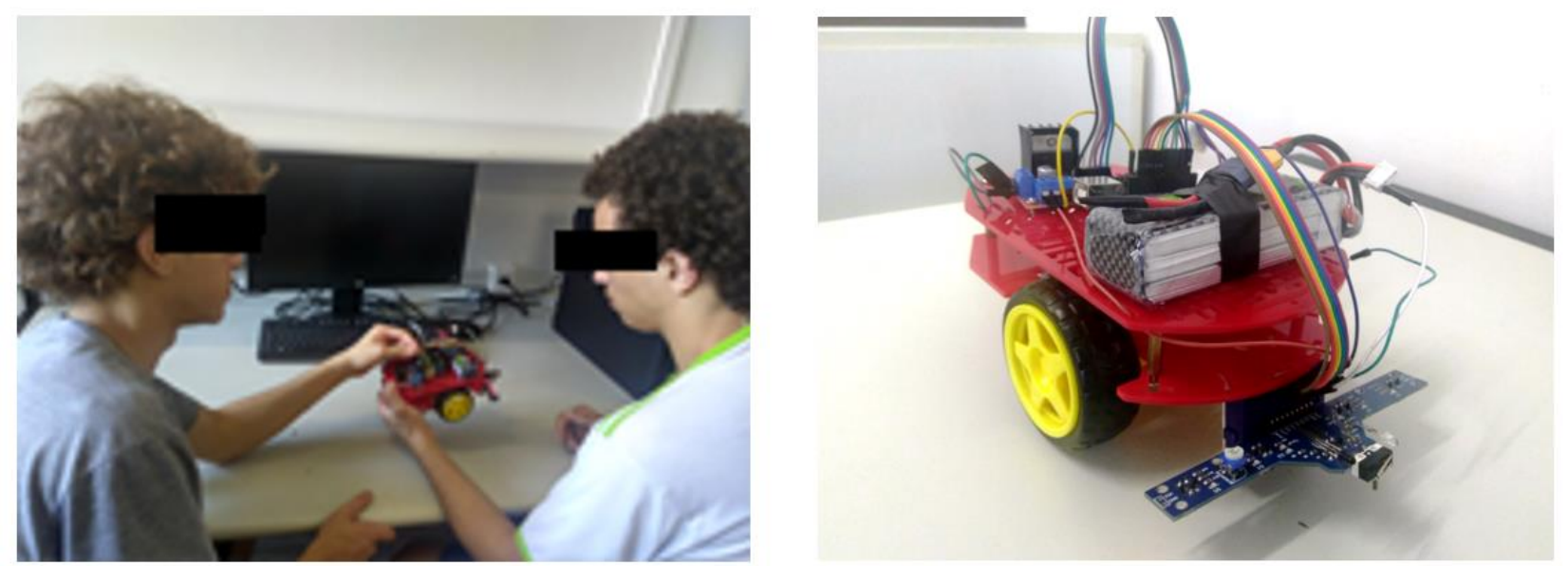
Os alunos se mostraram motivados com a resolução dos problemas e a abordagem pedagógica realizada.

\subsection{USO dA APRENDIZAGEM AUTÊNTICA NA VISÃO dOS ALUNOS}

Para avaliar a percepção dos alunos quanto à metodologia utilizada, foram elaboradas diversas perguntas com respostas na escala Likert de 5 pontos que variam de Pouco a Bastante. Apenas a sexta questão contém resultado binário (sim/não) e a última questão é referida a sugestões que o aluno poderia fornecer como feedback para melhoria da abordagem. Os alunos responderam os questionários e o levantamento das respostas é apresentado na Tabela 1 a seguir.

Tabela 1: Resumo dos resultados das 21 enquetes de acordo ao processo de ensinoaprendizagem utilizado.

\begin{tabular}{|c|c|c|c|c|c|c|c|}
\hline \multirow{2}{*}{ Enquete } & \multicolumn{7}{|c|}{ Perguntas } \\
\hline & $a$ & $b$ & $\mathrm{C}$ & $d$ & $\mathrm{e}$ & $f$ & Sugestões \\
\hline 1 & 3 & 4 & 5 & 3 & 4 & $\operatorname{sim}$ & Mais exercícios \\
\hline 2 & 3 & 3 & 4 & 4 & 5 & $\operatorname{sim}$ & \\
\hline 3 & 5 & 3 & 5 & 5 & 5 & não & Mais exercícios \\
\hline 4 & 4 & 2 & 5 & 5 & 4 & não & \\
\hline 5 & 5 & 3 & 4 & 5 & 5 & não & Mais exercícios \\
\hline 6 & 4 & 3 & 5 & 5 & 5 & não & Mais exercícios \\
\hline 7 & 4 & 4 & 5 & 4 & 4 & não & \\
\hline 8 & 3 & 2 & 4 & 1 & 4 & $\operatorname{sim}$ & Usar mais vezes o quadro \\
\hline 9 & 3 & 4 & 4 & 4 & 5 & $\operatorname{sim}$ & \\
\hline 10 & 3 & 4 & 3 & 5 & 4 & $\operatorname{sim}$ & Realizar mais perguntas \\
\hline 11 & 4 & 4 & 4 & 3 & 4 & $\operatorname{sim}$ & \\
\hline 12 & 4 & 4 & 5 & 5 & 4 & $\operatorname{sim}$ & \\
\hline 13 & 4 & 4 & 5 & 5 & 5 & não & \\
\hline 14 & 4 & 3 & 4 & 3 & 5 & $\operatorname{sim}$ & \\
\hline 15 & 4 & 4 & 4 & 3 & 5 & $\operatorname{sim}$ & \\
\hline 16 & 3 & 3 & 4 & 4 & 5 & $\operatorname{sim}$ & Mais exercícios \\
\hline 17 & 4 & 3 & 4 & 4 & 5 & $\operatorname{sim}$ & \\
\hline 18 & 4 & 2 & 3 & 2 & 3 & não & $\begin{array}{c}\text { Novos métodos de } \\
\text { avaliação }\end{array}$ \\
\hline 19 & 3 & 3 & 3 & 3 & 4 & $\operatorname{sim}$ & \\
\hline 20 & 4 & 3 & 4 & 5 & 4 & não & Mais exercícios \\
\hline 21 & 5 & 4 & 5 & 5 & 5 & não & \\
\hline Média & 3,81 & 3,29 & 4,24 & 3,95 & 4,48 & & \\
\hline
\end{tabular}


Para 14 alunos dos 21, os objetivos da disciplina foram alcançados com avaliação superior à média (pontuações 4 e 5). Para 9 dos alunos, as técnicas utilizadas ajudaram o entendimento dos conteúdos com avaliação superior à média (pontuações de nível 4). Para 18 dos alunos, as atividades fora e dentro da aula foram consistentes com avaliação superior à média (pontuações 4 e 5). Para 14 dos alunos, o aprendizado da matéria despertou o interesse por querer conhecer mais sobre o lecionado nas aulas com avaliação superior à média (pontuações 4 e 5). Para 20 dos alunos, o método de avaliação conseguiu detectar se houve aprendizado, apenas 1 aluno o qualificou com pontuação média (pontuação nível 3). Finalmente, para 12 alunos, esta abordagem representa uma experiência nova de ensino.

Um gráfico da denominada Análise da Variância (Analysis of variance- ANOVA) é mostrado na figura 8 , onde as linhas vermelhas indicam a mediana de acordo aos resultados da tabela 1.

Figura 8: Análise da Variância (ANOVA) dos resultados analisados na enquete, tendo como base as 21 enquetes realizados.

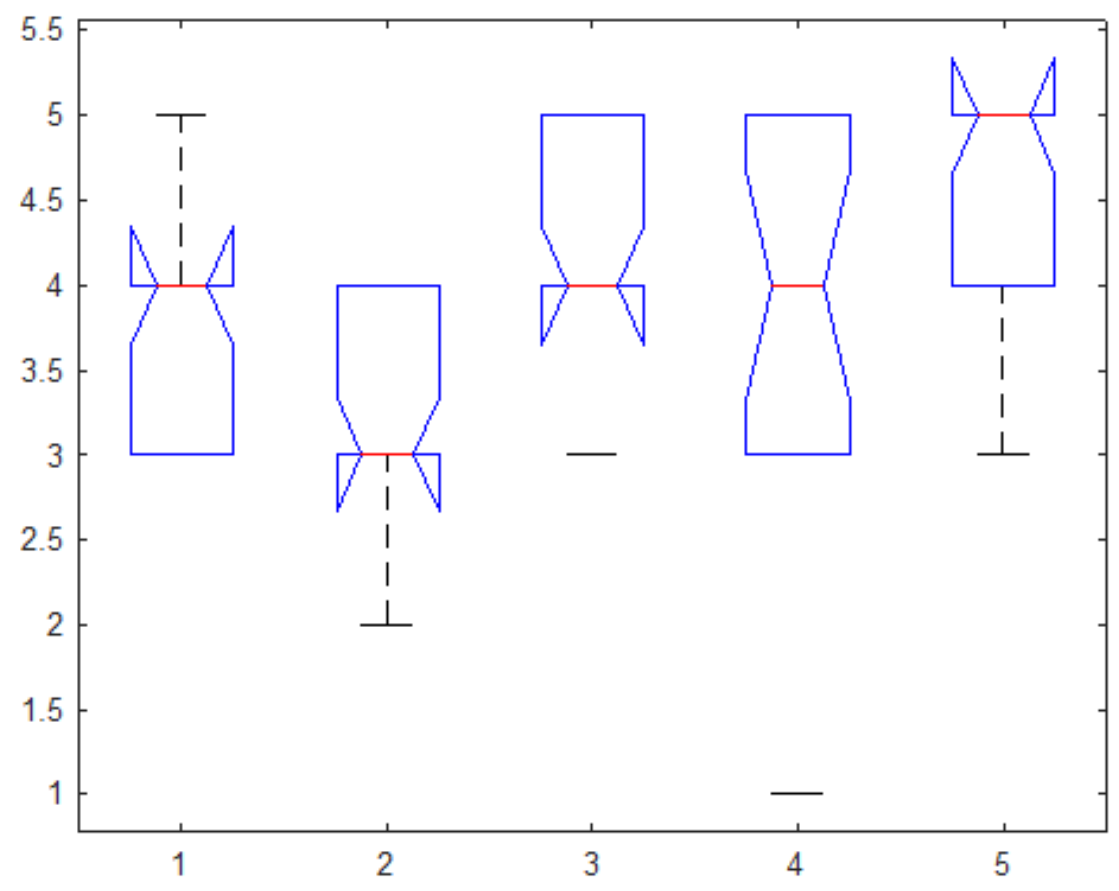


A avaliação da metodologia proposta na intervenção pedagógica teve resultados positivos para a melhora na aprendizagem dos alunos. Existe uma avaliação positiva do parecer dos alunos com referência à disciplina. Isto pode ser claramente observado segundo os resultados mostrados na análise ANOVA da Figura 8.

\section{CONSIDERAÇÕES FINAIS}

Quanto ao uso da aprendizagem autêntica com o apoio do uso da robótica educacional na aprendizagem de sistemas embarcados, pode-se dizer que a intervenção pedagógica para a materialização dos objetivos foi realizada. Um dos objetivos fundamentais da abordagem da aprendizagem autêntica foi encontrar soluciones a problemas da vida real. Sendo esta última, uma das principais motivações dos alunos. O fato de poder ir descobrindo soluções e ao mesmo tempo aprender os temas relacionados à disciplina foi da mesma forma, o objetivo do docente.

Os alunos se mostraram motivados e com desejo de aprender mais além do ministrado nas aulas. A partir das sugestões feitas pelos alunos, o fornecimento de mais exercícios tem se mencionado de forma frequente. Esta realimentação obtida pela enquete permitirá que em outros semestres possa ser aplicado o fornecimento de mais exercícios para serem realizados em casa.

Uma das sugestões também é o uso de mais vezes do quadro, entende-se que é o método tradicional de ensino. De acordo a esta sugestão, em outros semestres será equilibrado o uso do quadro e de apresentação por meio de slides. A dependência da instrução tradicional não é simplesmente uma escolha feita pelo corpo docente individual - os alunos geralmente preferem isso. Essa resistência à aprendizagem ativa pode ter mais a ver com seu desenvolvimento epistemológico do que uma preferência verdadeira pela passividade. 
Com base nestes princípios o aluno sente-se motivado de poder desenvolver soluções da vida corriqueira e ao mesmo tempo abordando os conteúdos necessários para adquirir expertises que as carreiras requerem.

\section{AGRADECIMENTOS}

Gostaria de agradecer a minha orientadora Profa. Marize Lyra Silva Passos, pelo apoio na orientação e as criteriosas revisões para o desenvolvimento deste trabalho. 


\section{REFERÊNCIAS}

ALIMISIS, D.; MORO, M.; MENEGATTI, E. Educational Robotics in the Makers Era. Advances in Intelligent Systems and Computing. Springer. 2017.

FERBELLONE, H. F.; EBERSPACHER, H. F. Lógica de programação: a construção de algoritmos e estruturas de dados. Pearson Prentice Hall, 3. Ed., São Paulo. 2005.

GERHARDT, T. E., SILVEIRA, D. T. Métodos de pesquisa. Porto Alegre: Editora da UFRGS, 2009. $120 \mathrm{p}$.

GIL, A. C. Métodos e técnicas de pesquisa social. 2. ed. São Paulo: Atlas. 2009.

GÜNTHER, H. Pesquisa qualitativa versus pesquisa quantitativa: esta é a questão. Disponível em: <http://www.scielo.br/pdf/ptp/v22n2/a10v22n2.pdf>. Acesso em: 12 mai. de 2013.

HERRINGTON, J. Learning to conduct Research by Doing. Activity Theory, Authentic Learning and Emerging Technologies: Towards a transformative higher education pedagogy. Florence: Taylor and Francis, pp 61-65, 2014.

HERRINGTON, J.; OLIVER. R.; REEVES, T. C. Patterns of engagement in authentic online learning environments. Australian Journal of Educational Technology, 19(1), 59-71. 2003. Disponível em: <http://www.ascilite.org.au/ajet/ajet19/herrington.html>.

HERRINGTON, J.; OLIVER, R. An instructional design framework for authentic learning environments. Educational Technology Research and Development, 48, 23-48, 2000.

HERRINGTON, J.; OLIVER, R. An Instructional Design Framework for Authentic Learning Environments. Educational Technology Research and Development, vol.48, no. 3 pp. 23-38, 2000.

JONASSEN, D.; HOWLAND, J.; MARRA, R.M.; CRISMOND, D. Meaningful learning with technology. 3. ed. Upper Saddle River: Pearson Education, Inc. 2008.

LOMBARDI, M. M. Authentic Learning for the 21st Century: An Overview (Boulder, CO: EDUCAUSE Learning Initiative), 2007. Disponível em: <http://www.educause.edu/ir/library/pdf/ELI3009.pdf>. Acesso em: 14 out. 2018.

LÜDKE, M.; ANDRÉ; M. E. D. A. Pesquisa em educação: abordagens qualitativas. Reimpr. São Paulo: E.P.U. 2012.

MALONEY, J.; BURD, L.; KAFAI, Y. Scratch: A Sneak Preview. In: Proceedings of the Second International Conference on Creating, Connecting and Collaborating through Computing (C5'04). 2004.

MONK, S. 30 Arduino Projects for the Evil Genius. McGraw-Hill/TAB Electronics, 2nd Edition, 2013. 
PADLET. Site oficial em português do Padlet, Disponível em: <https://ptbr.padlet.com/>. Acesso em: 11 set. 2018.

REEVES, T. C.; HERRINGTON, J.; OLIVER, R. Authentic activities and online learning. In: Annual Conference Proceedings of Higher Education Research and Development Society of Australasia. Perth, Austrália. 2002. Disponível em: <http://www.ecu.edu.au/conferences/herdsa/main/papers/ref/pdf/Reeves.pdf>.

RODRIGUES, A. de J. Metodologia científica. São Paulo: Avercamp, 2006.

RULE, A. C. Editorial: The components of authentic learning. Journal of Authentic Learning, 3(1), 1-10. Retrieved from Directory of Open Access Journals database. 2006.

SAMPIERI, R. H.; COLLADO, C. H.; LUCIO, P. B. Metodologia de pesquisa. México: McGraw-Hill International, 1991.

SMITH, A. G. Online and Distance Learning: Concepts., Methodologies, Tools and Applications, Online Information Review, Vol. 32 Issue: 2, Chapter 1.8. What is an Authentic Learning Environment?/Anthony Herrington and Jan Herrington. pp.288290, 2008. Disponível em: <https://doi.org/10.1108/14684520810879926> Acesso em: 14 out. 2018.

TERVAKARI, A.; SILIUS, K. Towards More Authentic Learning in Hypermedia. International Journal of Emerging Technologies in Learning (iJET), [S.I.], v. 6, p. pp. 5056. 2011.

WHITBURN, S.; ALLAN, P.; KEBBELL, S.; SCHNABEL, M. A. Interdisciplinary Authentic Learning: Adaptive Collaboration in Design Studios. 9th annual International Conference of Education, Research and Innovation, Seville, Spain. 14-16 November, 2016.

YOUNG, M. F.; MCNEESE, M. A situated cognition approach to problem solving with implications for computer-based learning and assessment. In G. Salvendy \& M.J. Smith (Eds.), Human-computer interaction: Software and hardware interfaces. New York: Elsevier Science Publishers, 1993.

YOUNG, M. F.; MCNEESE, M. A situated cognition approach to problem solving with implications for computer-based learning and assessment. Advances In Human Factors Ergonomics, v. 19, p. 825-825, 1993.

ZANETTI, H. A. P.; OLIVEIRA, C. L. V. Prática de ensino de Programação de Computadores com Robótica Pedagógica e aplicação de Pensamento Computacional. In: Anais dos Workshops do IV Congresso Brasileiro de Informática na Educação (CBIE 2015). 2015. 